\title{
MILLENNIAL CYCLES OF MEAN SEA LEVEL EXCITED BY EARTH'S ORBITAL VARIATIONS
}

\author{
Yavor CHAPANOV ${ }^{1) *}$, Cyril RON ${ }^{2)}$ and Jan VONDRÁK ${ }^{2)}$ \\ ${ }^{1)}$ National Institute of Geophysics, Geodesy and Geography, BAS Acad. G. Bonchev, Str. Bl.3, Sofia 1113, Bulgaria \\ ${ }^{2)}$ Astronomical Institute, Czech Academy of Sciences, Bočni II 1401, 14100 Prague 4, Czech Republic \\ *Corresponding author's e-mail: yavor.chapanov@gmail.com
}

\begin{tabular}{l} 
ARTICLE INFO \\
\hline Article history: \\
Received 14 January 2015 \\
Accepted 9 June 2015 \\
Available online 13 July 2015 \\
\hline
\end{tabular}

\section{Keywords:}

Millenial cycles

Mean sea level

Earth's insolation

\begin{abstract}
The millennial climate cycles are an important factor of global environmental changes. These cycles change the polar ice thickness during ice ages, what results in the Mean Sea Level (MSL) changes. The main cause of ice age periods are the so called Milankovich orbital cycles, generated by variations of climatic precession, eccentricity of the Earth's orbit and Earth's axial tilt with respect to its orbital plane with main periods of about $23 \mathrm{ka}^{1}, 40 \mathrm{ka}$ and $100 \mathrm{ka}$, respectively. The common millennial cycles of MSL and Earth's orbit variations are studied by means of reconstructed MSL time series for the last $800 \mathrm{ka}$ and insolation data of the latest orbital solution of Laskar et al. (2011). The models of the common millennial cycles of MSL and insolation variations are based on partial Fourier approximations with different period bands around $23 \mathrm{ka}, 18 \mathrm{ka}, 11.5 \mathrm{ka}, 7.5 \mathrm{ka}, 6 \mathrm{ka}$ and $2.3 \mathrm{ka}$, respectively. These models may help to analyze the Earth's rotation cycles caused by millennial solar activity cycles, such as Hallstatt cycles, and to point out new possible millennial cycles of the solar activity.
\end{abstract}

\section{INTRODUCTION}

Nowadays, it is well known that the continental ice sheets reached latitudes between $40^{\circ}$ and $50^{\circ}$ in the North America and between $50^{\circ}$ and $60^{\circ}$ in EuroAsia during the last glacial maximum. Roughly, this area is almost circular with radius $4400 \mathrm{~km}$ (corresponding to $40^{\circ}$ over the meridian). The center of this area is shifted by $10^{\circ}$ from the North Pole to the Greenland direction. The South Pole ice sheet covers almost circular area with latitude above $50^{\circ}$ (Paul and Schäfer-Neth, 2003; Schäfer-Neth and Paul, 2003), thus its radius is approximately the same as the North Pole ice sheet. These polar ice sheets are approximately $3 \mathrm{~km}$ thick and they lead to $110 \mathrm{~m}$ decrease of the mean sea level. In the Pleistocene, the Earth's climate was mostly in ice ages state, and the ice ages cycles have periods of $40 \mathrm{ka}$ or $100 \mathrm{ka}$. The glaciations cause significant MSL variations, water redistribution between the ocean and polar ice cap, and change of the Earth's axial moment of inertia, which is connected with long periodical variations of the Earth's rotation, expressed as Length of Day (LOD) and Universal Time (UT1) oscillations. It is possible to determine the long-term glacial variations of LOD and UT1 by means of the reconstructed paleo MSL data.

Recently, the MSL variations have been reconstructed for the last $380 \mathrm{ka}$ by Siddall et al. (2003). Highstands of sea level are reconstructed from dated fossil coral reef terraces, and these data are complemented by a compilation of global sea-level estimates based on ratios $\delta^{18} \mathrm{O}$ of deep-sea oxygen isotopes ${ }^{18} \mathrm{O}$ and ${ }^{16} \mathrm{O}$ fixed in shells in sedimentary data. The value of $\delta^{18} \mathrm{O}$ is used as a proxy of the global temperature using the fact that more ${ }^{18} \mathrm{O}$ implies more ice in continents and more ${ }^{16} \mathrm{O}$ implies less ice. Their reconstruction is accurate to within $\pm 12 \mathrm{~m}$, and gives a centennial-scale resolution.

Jouzel et al. (2007) estimate the mean temperature variations $T$ by means of a highresolution deuterium profile from Antarctica Dome C ice core, determined with a high relative accuracy of about $0.5 \%$. They extend this deuterium climate record back to $\sim 800 \mathrm{ka}$ ago and provide temperature interpretation of the data by an atmospheric general circulation model including water isotopes. Their time scale is in excellent agreement with the Dome Fuji and Vostok ice core time scales within $1 \mathrm{ka}$ for significant data parts (Parrenin et al., 2007). This difference is a systematic long term shift between different data sets and it is visible like a time lag in comparison with the millennial cycles of climate, MSL and insolation time series, while the time scale random errors stay at centennial level. The MSL and $T$ variations are strongly correlated. It is possible to reconstruct MSL variations for the period 380-800 ka before present (BP) by a regression model $\mathrm{MSL}=7.4 T-18.7$, where MSL variations are in meters and $T$ in ${ }^{\circ} \mathrm{C}$ (Fig. 1). 


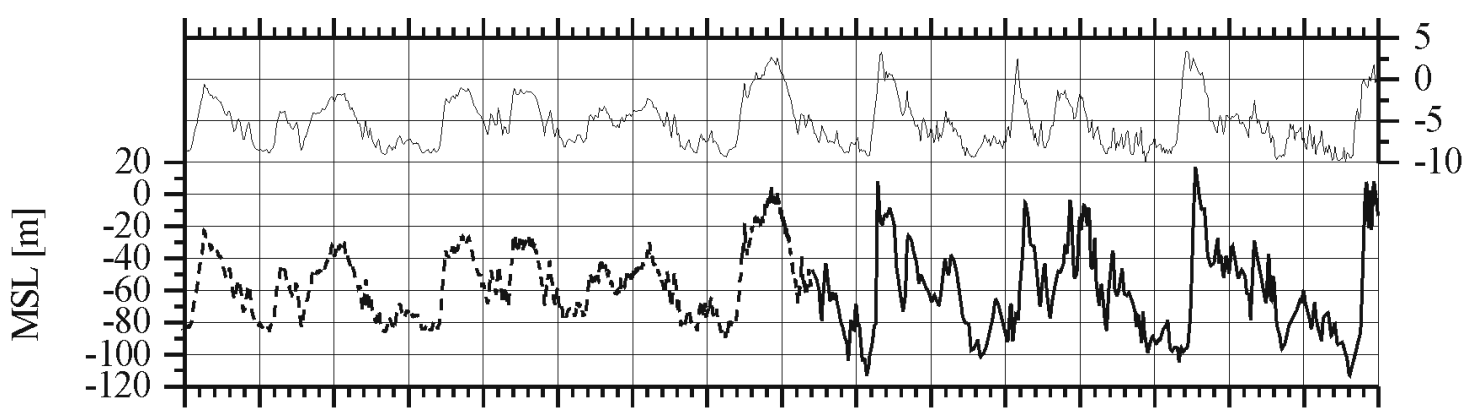

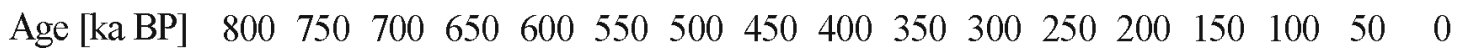

Fig. 1 Antarctic temperature T (thin line) for the last 800ka, MSL variations for 0-380 ka BP (bold line, Siddall et al., 2003) and MSL for 380-800 ka BP, determined by a linear regression between T and MSL data (dashed line).

A century ago, Croll (1864) and Milankovich (1920) suggested that the ice ages have astronomical reasons. Nowadays, the science community accepts that the fundamental sources of ice ages are the long term variations of the Earth's orbit according to Milankovich theory (Milankovich, 1998). Significant oscillations in total and local Earth's insolation are caused by the variations of the following orbital elements:

- the eccentricity has several periods around $100 \mathrm{ka}$;

- the obliquity of the Earth's axis, that is the tilt with respect to the normal to the ecliptic plane, oscillates with a period of about $41 \mathrm{ka}$;

- the precession of the equinoxes with period of $25.8 \mathrm{ka}$;

- the 'climatic' precession (Loutre, 2009), defined by formula $e \sin (w)$, where $e$ means eccentricity and $w$ the longitude of perihelion from the moving equinox, presenting two main modes at $23 \mathrm{ka}$ and $19 \mathrm{ka}$.

Smaller changes of the insolation are associated with other Earth's Keplerian elements, namely semimajor axis, inclination of the ecliptic in relation to J2000 reference frame and longitude of perihelion, whose variations can modulate the local Earth's insolation. The most accurate eccentricity, climatic precession, obliquity, and insolation for the past several millions years have been proposed by Laskar et al. (2011). The other elements: semi-major axis, inclination and longitude of perihelion are calculated by the program Mercury 6 (Chambers and Migliorini, 1997). The most important factors of ice age cycles are the local summer insolation at $65^{\circ} \mathrm{N}$ latitude, and the climatic precession.

Some authors consider that the orbital variations may explain only one half of reconstructed temperature variations derived from sea sediments and polar ice core drilling (Imbrie et al., 1992; 1993). They propose a function of the orbital components, which approximates the observed paleoclimatic variations better than the Milankovich theory (Imbrie,
1985; Imbrie et al., 1992, 1993). Another important step toward the improvement of the astro-paleo theory is made in the publications of Shopov et al. (1999, 2001, 2004), where the influence of some millennial cycles with periods up to 11500 years of the solar activity on the paleo climate is suggested.

\section{DATA AND METHOD OF ANALYSIS}

The latest high-precise series of the Earth's orbital and insolation changes mentioned above are shown in Figures 2 and 3. The semi-major axis (Fig. 2) remains very close to $1 \mathrm{au}$, presenting relative variations up to $10^{-5}$ au. Its oscillations are not smooth, so that they are not readily describable by Fourier series. On the contrary, the variations of the other Keplerian elements (Fig. 2) and of the obliquity (Fig. 3) are rather smooth, yielding harmonics below $25 \mathrm{ka}$. As a function of the obliquity (Fig. 3) and of all orbital elements, the summer insolation at $65^{\circ} \mathrm{N}$ latitude (Fig. 3) has a lot of cycles below $25 \mathrm{ka}$.

The millennial astronomical and climate cycles are represented by partial Fourier series, the coefficients of which are derived by the Least-Squares Method (LS).

The partial sum of Fourier series $F(t)$ of discrete data $f_{i}$ is given by

$$
\begin{aligned}
& F(t)=f_{0}+f_{l}\left(t-t_{0}\right)+\sum_{k=1}^{n} a_{k} \sin \left[k \frac{2 \pi}{t_{E}-t_{B}}\left(t-t_{0}\right)\right]+ \\
& +b_{k} \cos \left[k \frac{2 \pi}{t_{E}-t_{B}}\left(t-t_{0}\right)\right],
\end{aligned}
$$

where $t_{0}, t_{B}$ and $t_{E}$ are the mean, first and last epochs of observations, respectively, $f_{0}, f_{l}, a_{k}$ and $b_{k}$ are unknown coefficients and $n$ is the number of harmonics of the partial sum, which covers all oscillations with periods between $\left(t_{E}-t_{B}\right) / n$ and $\left(t_{E}-t_{B}\right)$. The application of the LS estimation of Fourier coefficients needs at least $2 n+2$ observations, so the number of harmonics $n$ is chosen significantly smaller than the number $N$ of sampled data $f_{i}$. The small number of harmonics $n$ yields to LS estimation of the coefficient errors, too. The period of the first long- 


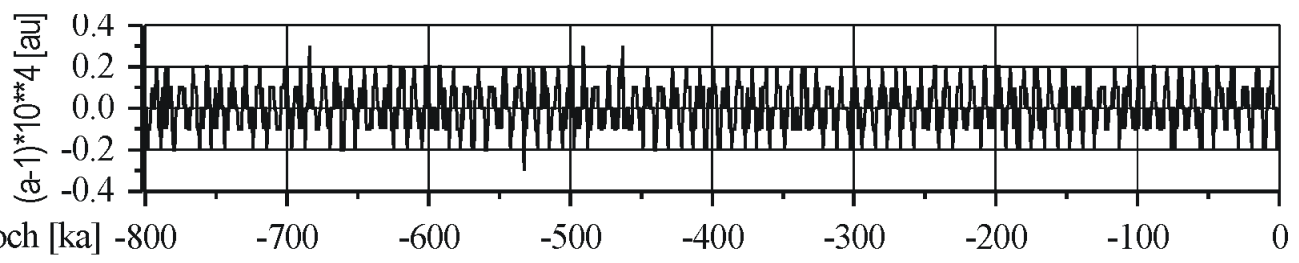

Epoch $[\mathrm{ka}]-800$

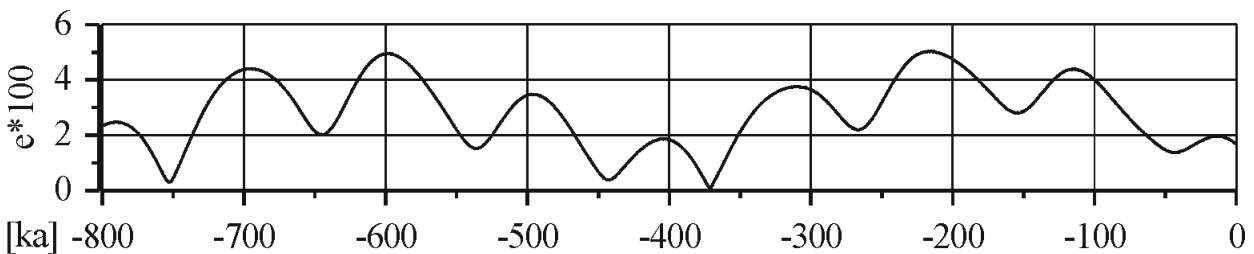

Epoch [ka] -800

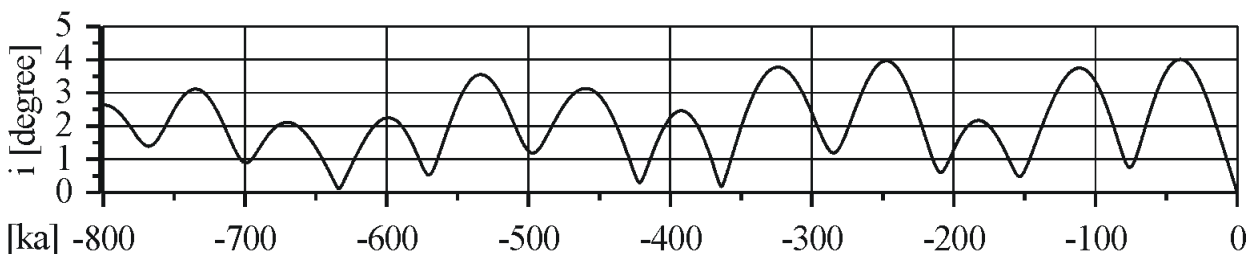

Epoch [ka] -800

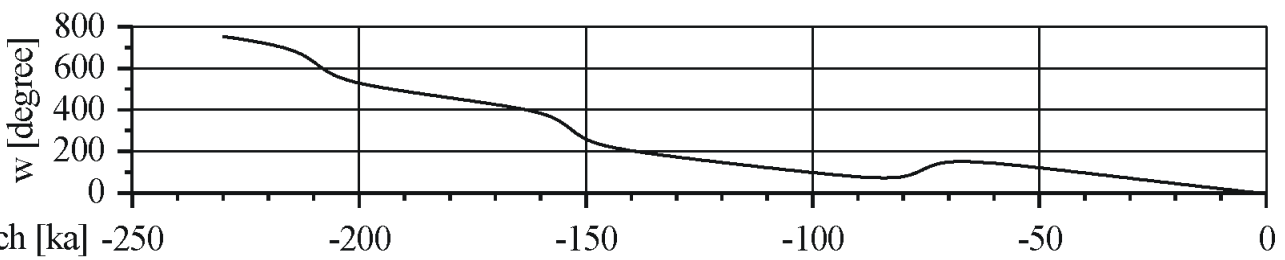

Fig. 2 Paleo variations of keplerian elements of Earth's orbit - semi-major axis $a$, eccentricity $e$, inclination $i$ and longitude of perihelion $w$.

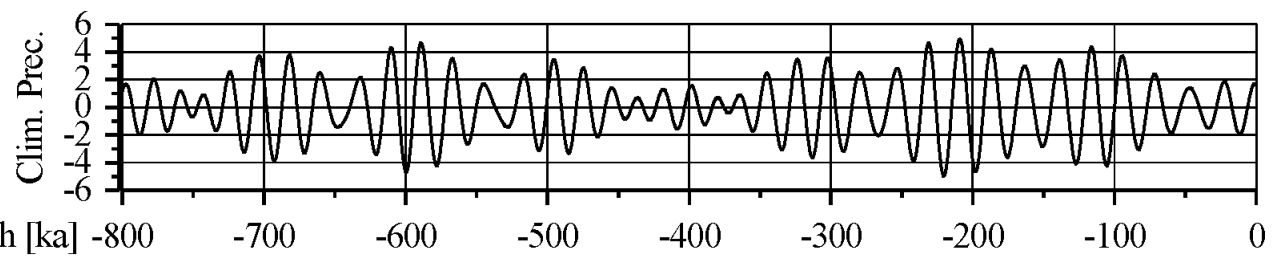

Epoch [ka] -800
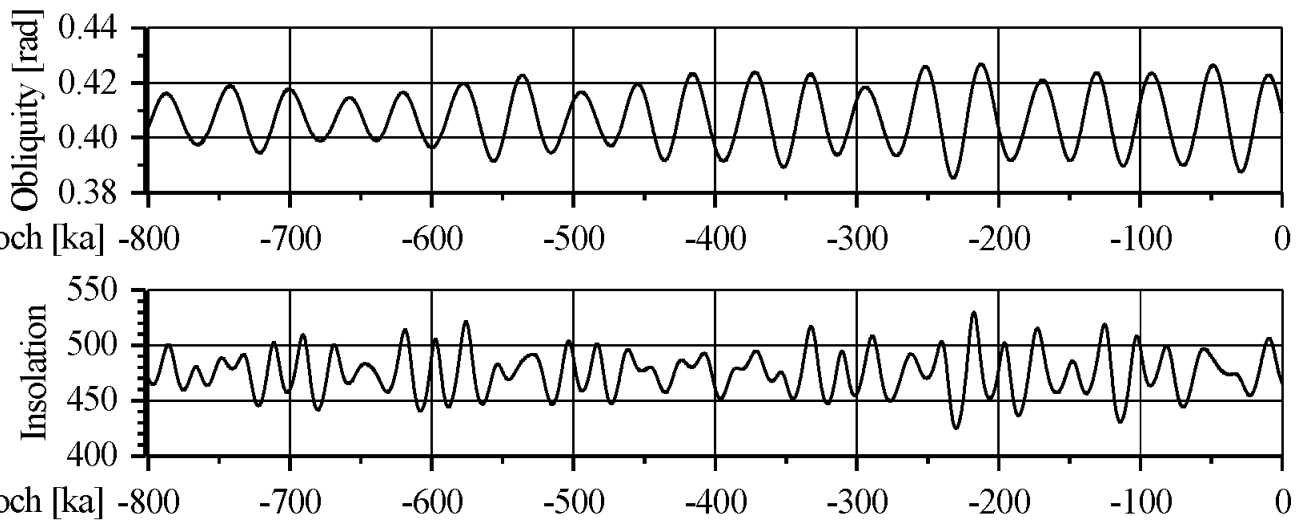

Fig. 3 Paleo variations of climatic precession (x100), obliquity and summer insolation at $65^{\circ}$ $\mathrm{N}$ latitude $\left(\mathrm{W} / \mathrm{m}^{2}\right)$. 
Table 1 Accuracy of estimated amplitudes by the Least Squares Method.

\begin{tabular}{lcc}
\hline Element & Harmonics 1-10 & Harmonics 11-200 \\
\hline Longitude of perihelion [degree] & $0.3 \div 2.1$ & 0.28 \\
\hline Inclination [degree] & $5 \times 10^{-6} \div 32 \times 10^{-6}$ & $4.2 \times 10^{-6}$ \\
\hline MSL [cm] & $8 \div 54$ & 6 \\
\hline Insolation $65^{\circ} \mathrm{N}\left[\mathrm{mW} / \mathrm{m}^{2}\right]$ & $0.4 \div 2.8$ & 0.3 \\
\hline Climatic precession $\times 100$ & $2 \times 10^{-4} \div 1 \times 10^{-3}$ & $1 \times 10^{-4}$ \\
\hline
\end{tabular}
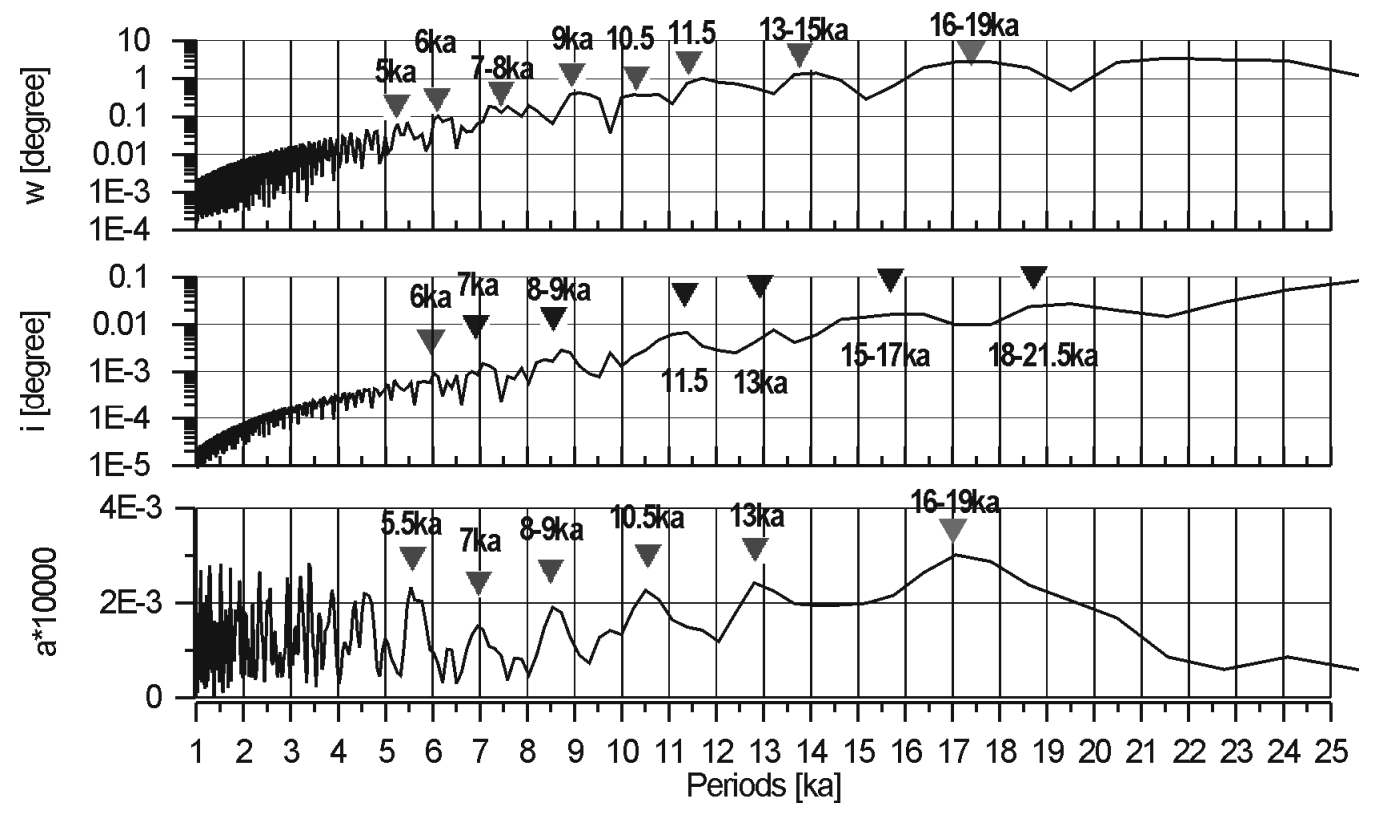

Fig. 4 Spectra of paleo variations of Earth's orbital elements: semi-major axis $a$, inclination $i$ and longitude of perihelion $w$.

periodical harmonic in (1) depends on the observational time span in case of classic Fourier approximation, but here it is possible to decrease this value so that the estimation may cover the whole set of desired frequencies. This method allows a flexible separation of the harmonic oscillations into different frequency bands by the formula

$$
\begin{aligned}
B(t) & =\sum_{k=m_{1}}^{m_{2}} a_{k} \sin \left[k \frac{2 \pi}{t_{E}-t_{B}}\left(t-t_{0}\right)\right]+ \\
& +b_{k} \cos \left[k \frac{2 \pi}{t_{E}-t_{B}}\left(t-t_{0}\right)\right],
\end{aligned}
$$

where the desired frequencies $\omega_{k}=k \frac{2 \pi}{t_{E}-t_{B}}$ are limited by the bandwidth

$$
\frac{2 \pi m_{1}}{t_{E}-t_{B}} \leq \omega_{k} \leq \frac{2 \pi m_{2}}{t_{E}-t_{B}}
$$

After estimating the Fourier coefficients, it is possible to identify a narrow frequency zone presenting significant amplitude, and defining a given cycle. Then this cycle can be reconstructed in time domain as the partial sum limited to the corresponding frequency bandwidth. Doing this for climate, orbital and solar insolation time series, we shall identify their respective cycles, isolate and compare the common ones.

\section{TIME SERIES SPECTRA}

As already pointed out, the paleo variations of semi-major axis $a$ (Fig. 2) are not sufficiently smooth and its spectrum is determined by the Fast Fourier Transform (FFT). The amplitude spectra of inclination $i$, longitude of perihelion $w$ on one hand (Fig. 4), MSL, summer insolation at $65^{\circ} \mathrm{N}$ latitude and climatic precession on the other hand (Fig. 5) are determined by partial sums of Fourier series covering $800 \mathrm{ka}$ data and composed of 200 harmonics. The amplitudes $A_{k}$ of these harmonics are calculated from the Fourier coefficients $a_{k}$ and $b_{k}$ by the expression

$A_{k}=\sqrt{a_{k}^{2}+b_{k}^{2}}$

and their accuracy is given in Table 1. 


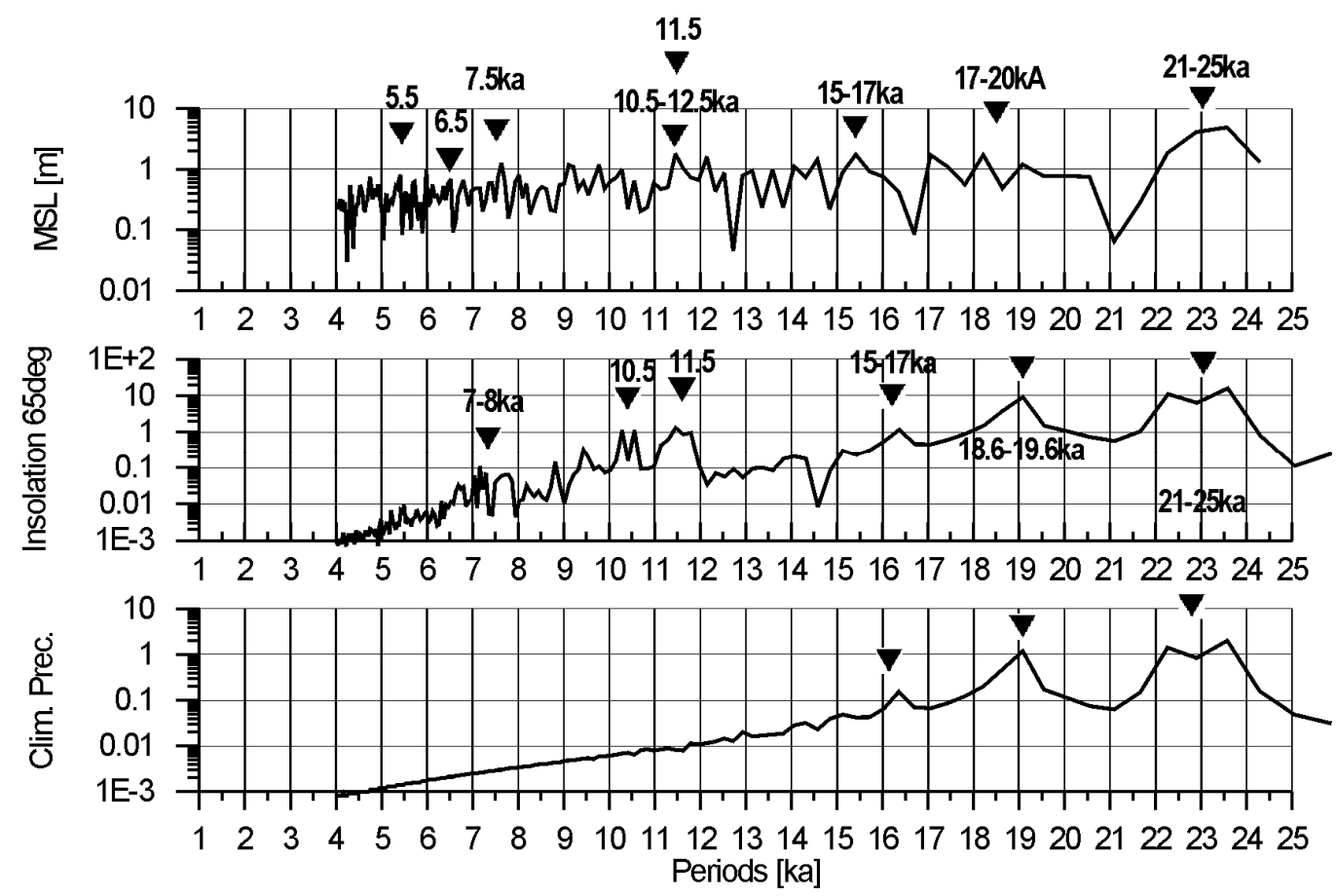

Fig. 5 Spectra of paleo variations of MSL, insolation at $65^{\circ} \mathrm{N}$ latitude and climatic precession.
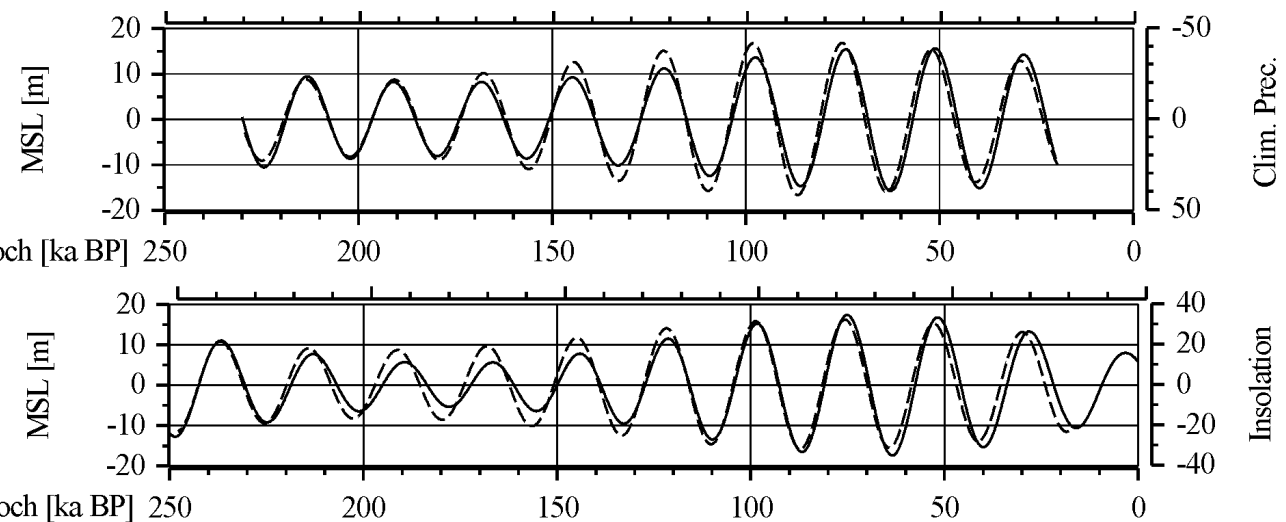

Epoch [ka BP] 250

200

150

100

50

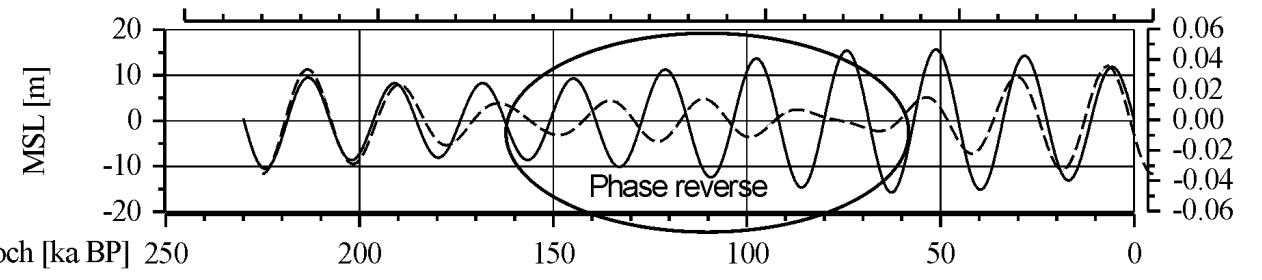

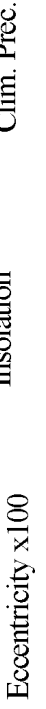

Fig. 6 Common cycles in the band 21-25 ka between MSL and climatic precession/ insolation at $65^{\circ} \mathrm{N}$ latitude/ eccentricity.

Comparing the spectra of orbital elements and MSL, we put forward 6 common frequency bands with periods below $25 \mathrm{ka}$ : $21-25 \mathrm{ka} ; 18.6-19.6 \mathrm{ka}$; 13-17 ka; $11.3-11.8 \mathrm{ka} ; 7.5-7.8 \mathrm{ka} ; 5.9-6.0 \mathrm{ka}$. Two of these bands include the periods of $6 \mathrm{ka}$ and $11.5 \mathrm{ka}$, the origin of which could be linked with the solar activity (Xapsos and Burke, 2009; Shopov et al. 1999, 2001, 2004). Their solar activity origin can be checked by detecting discrepancy between orbital insolation and MSL variations. Additional frequency band with periodicity 2.25-3.0 ka (not presented in spectra of Figs. 4 and 5) is also involved, because it contains the well-established millennial cycle of the solar activity (Hallstatt cycle of $2.3 \mathrm{ka}$ ).

\section{COMMON MILLENNIAL CYCLES OF MSL, INSOLATION AND ORBITAL ELEMENTS}

All millennial cycles above $5 \mathrm{ka}$ of Earth's orbital elements, summer insolation at $65^{\circ} \mathrm{N}$ and MSL are determined by recontructing the partial Fourier series in time domain, whose periods belong to the chosen band. 


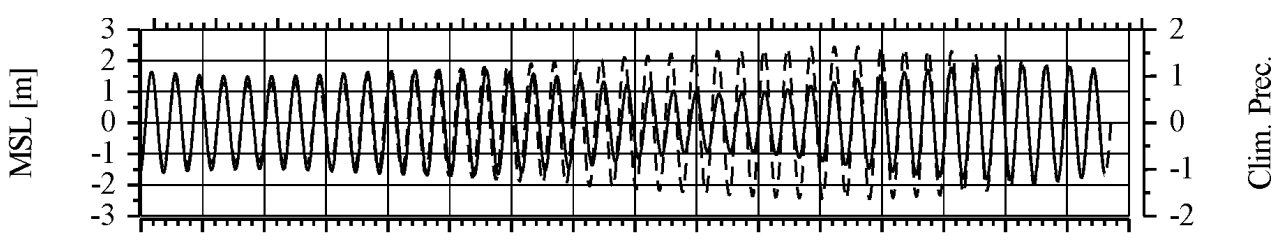

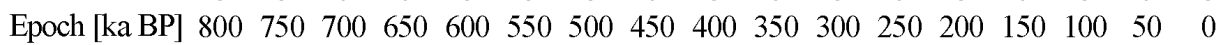

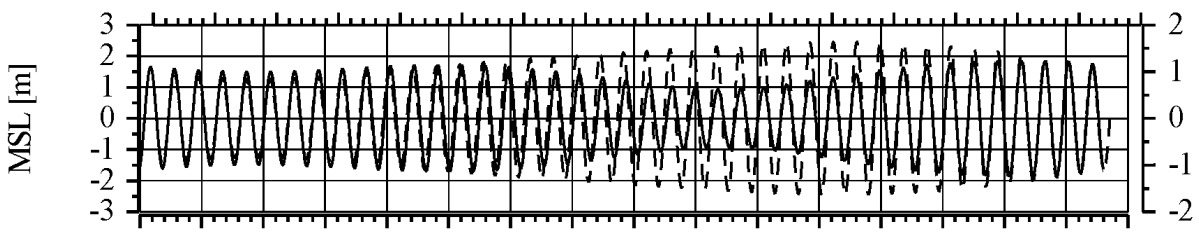

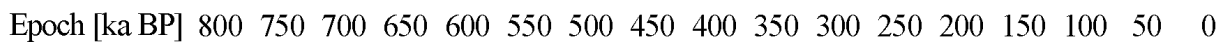

Fig. 7 Common cycles in the band 18.6-19.6ka between MSL and climatic precession / insolation at $65^{\circ} \mathrm{N}$ latitude.

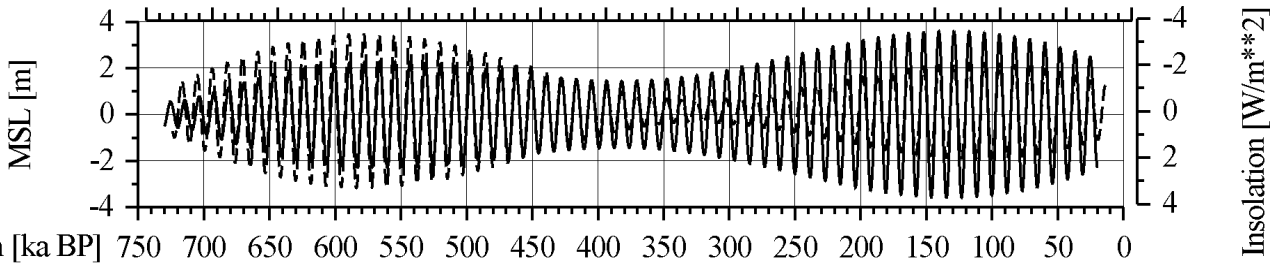

Fig. 8 Common cycles in the band $11.3-11.8 \mathrm{ka}$ of MSL and insolation at $65^{\circ} \mathrm{N}$ latitude.

\subsection{PERIOD BAND 21-25 KA}

The millennial cycles of MSL, insolation, climatic precession and eccentricity in the band 21$25 \mathrm{ka}$ (Fig. 6) are determined by 8 harmonics of Fourier approximations with numbers $k$ between 31 and 38. The MSL variations express excellent agreement in phase and amplitude with the insolation and climatic precession over $200 \mathrm{ka}$ time scales. The comparison of MSL and eccentricity shows phase inversion and amplitude disagreement, so we will compare MSL only with insolation and climatic precession.

\subsection{PERIOD BAND 18.6-19.6 KA}

The common orbital and climate cycles with periods from the band $18.6-19.6 \mathrm{ka}$ (Fig. 7) are determined by 3 harmonics of Fourier approximations with numbers $k$ between 41 and 43 . The MSL cycles express good agreement with the insolation and climatic precession with negligible phase and amplitude differences over $800 \mathrm{ka}$ time span, so we may suppose that these cycles have an orbital origin only.

\subsection{PERIOD BANDS 13-15 KA AND 15-17 KA}

Whereas these bands are common in spectra of Earth's orbital elements and climatic indices, it was not possible to find any combination of harmonics with periods between $13 \mathrm{ka}$ and $17 \mathrm{ka}$, whose superposition yields similar behavior between the orbital and climatic time series. This probably results from the existence of one or more disturbing cycles having no relation with orbital modulation of the insolation. The solar activity is a good candidate.

\subsection{PERIOD BAND 11.3-11.8 KA}

The common orbital and climate cycles with periods in the band $11.3-11.8 \mathrm{ka}$ (Fig. 8) are determined by 4 harmonics of Fourier approximations with numbers $k$ between 68 and 71. The MSL phase variations express excellent agreement with the insolation over $800 \mathrm{ka}$ time span, so the presence of any oscillation originating in the solar activity is very unlikely, in contrary to the previous band. Obviously, the MSL oscillations with period of about $11.5 \mathrm{ka}$ are of orbital origin, connected with the half period of climatic precession (23 ka).

\subsection{PERIOD BAND 7.5-7.8 KA}

The common orbital and climate cycles with periods in the band 7.5-7.8 ka (Fig. 9) are determined by 5 harmonics of Fourier approximations with numbers $k$ between 103 and 107. The MSL exhibits phase reversal with the insolation, so that the solar activity can eventually perturb this cycle.

\subsection{PERIOD BAND 5.9-6.0 KA}

The MSL and insolation cycles in the band 5.9$6.0 \mathrm{ka}$ (Fig. 10) are determined by 4 harmonics of Fourier approximations with numbers $k$ between 133 and 136. This band should contain the $6 \mathrm{ka}$ solar activity cycle mentioned in (Xapsos and Burke, 2009; Shopov et al., 1999, 2001, 2004). Actually, the phase variations of MSL and insolation over $800 \mathrm{ka}$ time 


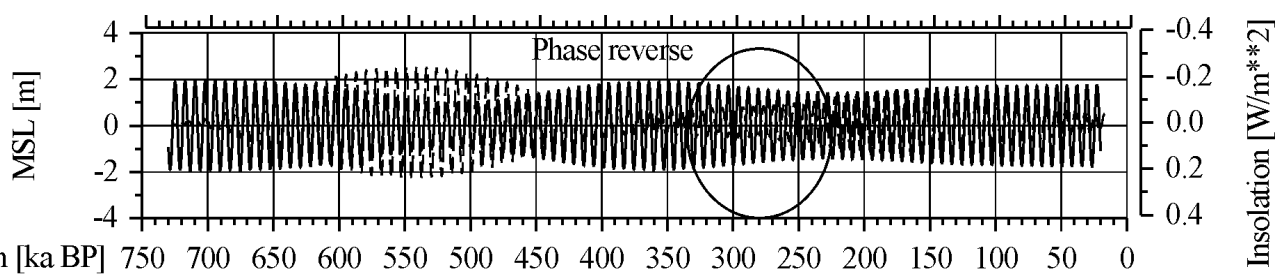

Fig. 9 Common cycles in the band 7.5-7.8ka between MSL and insolation at $65^{\circ} \mathrm{N}$ latitude.

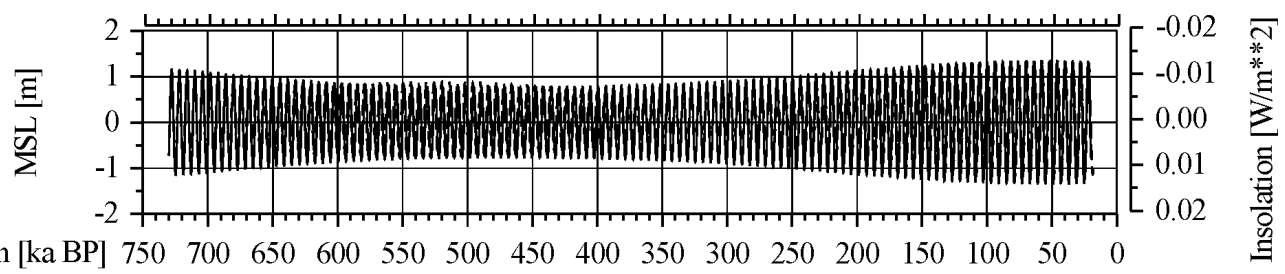

Fig. 10 Common cycles in the band 5.9-6.0ka between MSL and insolation at $65^{\circ} \mathrm{N}$ latitude.

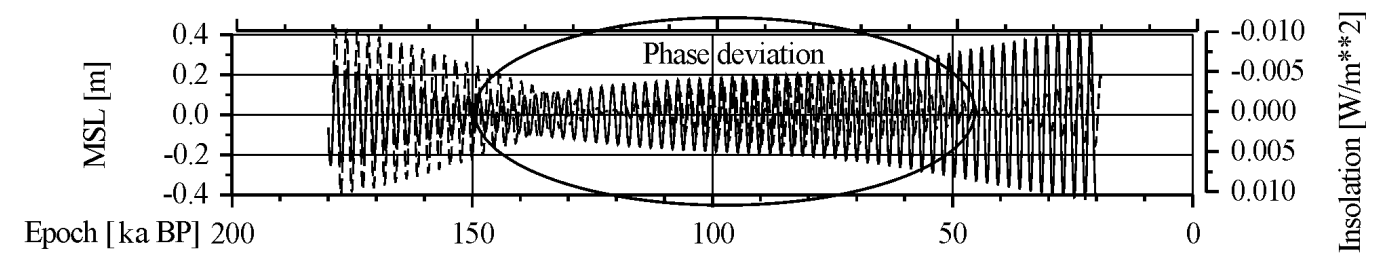

Fig. 11 Common cycles in the band 2.25-2.3ka between MSL and insolation at $65^{\circ} \mathrm{N}$ latitude.

span are in good agreement, only a small amplitude deviation between $200 \mathrm{ka}$ and $400 \mathrm{ka}$ BP exists. So, we conclude that if the solar activity cycle exists with the exact period of $6 \mathrm{ka}$, then its amplitude is small compared to orbital influences. Most probably, such solar cycle have rather long period, between $6 \mathrm{ka}$ and $7.8 \mathrm{ka}$.

\subsection{PERIOD BAND 2.25-3.0 KA}

As this period band is rather narrow, the corresponding oscillations are determined by superposing only 3 harmonics with numbers $k 100$, 101102 in the partial sum of Fourier series of MSL and insolation data for the period 0-230 ka BP (Fig. 11). As expected, the orbital-climatic influence is strongly disturbed by the Hallstatt solar cycle in this band, as evidenced by the strong phase and amplitude discrepancy between the summer $65^{\circ} \mathrm{N}$ insolation and MSL, for this band.

\subsection{RELATIONS TO THE VARIATIONS OF EARTH ROTATION AND PRINCIPAL MOMENTS OF INERTIA}

The Earth shape, gravity and rotation are highly affected by climatic variations associated with the glacial cycles in the late Pleistocene. The processes of glaciation, followed by ice melting and significant changes of the mean sea level redistribute great amount of water masses between oceans and ice sheets, which lead to changes of the principal moments of inertia. Chapanov and Gambis (2010, 2011) proposed models of Length of Day LOD, Universal Time UT1 and Earth principal moments of inertia $A, B, C$ as polynomial functions of the MSL. As illustrated in Figure 12 over the period $0-800 \mathrm{ka}$ $\mathrm{BP}$, these models reproduced almost linearly the shape of the MSL. Thus, all MSL millennial harmonics with periodicities below $25 \mathrm{ka}$, should be valid for the millennial cycles of Earth rotation and principal moments of inertia. This may help in better reconstructing and understanding paleo Earth rotation.

\section{CONCLUSIONS}

The Mean Sea Level and climatic insolation are decomposed in partial Fourier series over the last $800 \mathrm{ka}$. This allows us to identify 7 common millennial cycles with periods below $25 \mathrm{ka}$, and given by the bands $21-25 \mathrm{ka}, 18.6-19.6 \mathrm{ka}, 13-17 \mathrm{ka}, 11.3$ $11.8 \mathrm{ka}, 7.5-7.8 \mathrm{ka}, 5.9-6.0 \mathrm{ka}$ and $2.25-3.0 \mathrm{ka}$. The MSL oscillations express good agreement with the corresponding insolation in the bands $21-25 \mathrm{ka}, 18.6$ $19.6 \mathrm{ka}, 11.3-11.8 \mathrm{ka}$ and 5.9-6.0 ka, leading us to conclude that MSL millennial cycles are mostly due to orbital variations. However, the MSL and insolation oscillations have different amplitude and phase behavior for the period bands $13-17 \mathrm{ka}, 7.5-7.8 \mathrm{ka}$ and 2.25-3.0 ka. The last band contains the wellknown Hallstatt solar cycle, which produces 

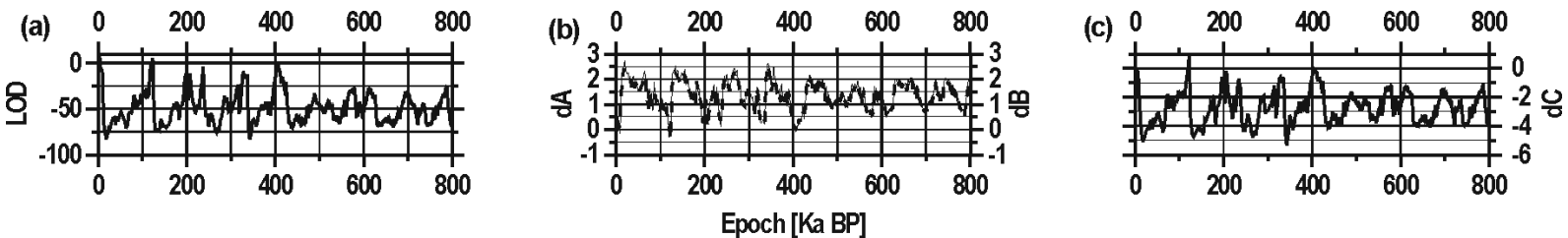

Fig. 12 Variations of LOD in $m s$ - (a), Earth inertial moments $A$ (thin line), $B$ (dashed line) in $k g m^{2} \times 10^{17}-$ (b) and axial moment $C$ in $\mathrm{kg} \mathrm{m}^{2} \times 10^{29}-$ (c) (Chapanov and Gambis, 2011).

significant disturbances of orbital-climatic influences. The discrepancy between the orbital and MSL cycles in the band 13-17 $\mathrm{ka}$ and 7.5-7.8 $\mathrm{ka}$ evidences an additional excitation. As the 2.3 ka Hallstatt cycle of solar activity disturbs the agreement between MSL and orbital insolation index, we assume that this additional excitation could originate in hypothetic solar cycles with the periods of 7-8 ka and 13-17 ka.

\section{ACKNOWLEDGEMENTS}

This research was financially supported by the grant No. 13-15943S "Geophysical excitations in the motion of Earth's axis of rotation" awarded by the Grant Agency of the Czech Republic. The support given to authors by Bulgarian and Czech Academies of Sciences in frame of Joint Research Project "Periodical and impulse variations of geodetic time series" is appreciated. We express our thanks to $\mathrm{Ch}$. Bizouard and an anonymous reviewer, whose constructive criticism and comments helped improve the text significantly.

\section{REFERENCES}

Chambers, J.E. and Migliorini, F.: 1997, Mercury - A New Software Package for Orbital Integrations. Bull. American Astron. Soc., 29, 1024.

Chapanov, Ya. and Gambis, D.: 2010, Long-periodical variations of Earth rotation, determined from reconstructed millennial-scale glacial sea level. Proc. BALWOIS 2010, Ohrid, 25-29 May, 2010, http://www.balwois.com/balwois/administration/full_ paper/ffp-1509.pdf.

Chapanov, Ya. and Gambis, D.: 2011, Variations of the Earth principal moments of inertia due to glacial cycles for the last $800 \mathrm{Ka}$. Proc. Journees "Systèmes de référence spatio-temporels", Paris, 198-199.

Croll, J.: 1864, On the physical cause of the change of climate during geological epochs. Philosophical Magazine, 28, 121-137.

Imbrie, J.: 1985, A theoretical framework for the Pleistocene Ice Ages. J. Geol. Soc. London, 142, $417-$ 432.

Imbrie, J. and 16 coauthors: 1992, On the structure and origin of Major Glaciation Cycles 1. Linear Responses to Milankovich Forcing. Paleoceanography, 7(6), 701-736.

Imbrie, J. and 16 coauthors: 1993, On the structure and origin of Major Glaciation Cycles 2. The 100,000-year Cycle. Paleoceanography, 8(6), 669-735.

Jouzel, J. and 31 coauthors: 2007, Orbital and millennial Antarctic climate variability over the past 800,000 years. Science, 317, No. 5839, 793-797.

DOI: $10.1126 /$ science 1141038
Laskar, J., Fienga, A., Gastineau, M. and Manche, H.: 2011, La2010: A new orbital solution for the long-term motion of the Earth. Astron. Astrophys., 532, A89. DOI: $10.1051 / 0004-6361 / 201116836$

Loutre, M.F.: 2009, Climatic precession. In: V. Gornitz (Ed.) Encyclopedia of Paleoclimatology and Ancient Environments, Springer Science \& Business Media, Dordrecht, $1047 \mathrm{pp}$.

Milankovich, M.: 1920, Thorie mathématique des phénomenes thermiques produits per la radiation solaire. Gauthier-Villars et Cie, Paris, 338 pp.

Milankovich, M.: 1998, Canon of insolation and ice-age problem (editors: Pijanovich, P. and Marjanovich, M. (eds.)), Beograd, 634.

Parrenin, F., and 26 coauthors: 2007, The EDC3 chronology for the EPICA Dome C ice core. Climate of the Past, 3, 485-497. DOI: $10.5194 / \mathrm{cp}-3-485-2007$

Paul, A., and Schäfer-Neth, C.: 2003, Modeling the water masses of the Atlantic Ocean at the Last Glacial Maximum. Paleoceanography, 18, No. 3, 1058. DOI: 10.1029/2002PA000783

Schäfer-Neth, C. and Paul, A.: 2003, The Atlantic Ocean at the last glacial maximum: 1 . Objective mapping of the GLAMAP sea-surface conditions. In: G. Wefer, S. Mulitza, and V. Ratmeyer (eds.) The South Atlantic in the Late Quaternary: Material Budget and Current Systems, Springer-Verlag, Berlin, Heidelberg, 531548.

Siddall, M., Rohling, E.J., Almogi-Labin, A., Hemleben, C., Meischner, D., Schmelzer, I., and Smeed, D.A.: 2003, Sea-level fluctuations during the last glacial cycle. Nature, 423, 853-858. DOI: 10.1038/nature01690

Shopov, Y.Y., Stoykova, D.A., Ford, D., Georgiev, L.N., Tsankov, L. and Georgieva, D.: 1999, Influence of variations of the Earth's orbit and solar luminosity on the sea level changes - Bulgarian contribution to Sea \& Space Event of Expo-98. Publ. Astron. Obs. Belgrade, No. 64, 95-102.

Shopov, Y, Stoykova, D., Tsankov, L., Sanabria, M., Georgieva, D. Ford, D., Lundberg, J., Georgiev, L. and Forti, P.: 2001, Intensity of prolonged solar luminosity cycles and their influence over past climates and geomagnetic field. Proc. 13th Int. Cong. of Speleology, 275-278.

Shopov, Y., Stoykova, D., Tsankov, L., Sanabria, M., Georgieva, D., Ford, D. and Georgiev, L.: 2004, Influence of solar luminosity over geomagnetic and climatic cycles as derived from speleothems. International Journal of Speleology, 33, No. 1-4, 1924.

Xapsos, M.A., and Burke, E.A.: 2009, Evidence of 6,000year periodicity in reconstructed sunspot numbers. Solar Phys., 257, No. 2, 363-369. DOI: $10.1007 / \mathrm{s} 1207-009-9380-3$ 